\title{
Deriving Mixed-Phase Cloud Properties from Doppler Radar Spectra
}

\author{
MatThew D. Shupe \\ Science and Technology Corporation, and NOAA/Environmental Technology Laboratory, Boulder, Colorado \\ Pavlos Kollias and Sergey Y. Matrosov \\ Cooperative Institute for Research in the Environmental Sciences, and NOAA/Environmental Technology Laboratory, Boulder, Colorado \\ TIMOTHY L. SCHNEIDER \\ NOAA/Environmental Technology Laboratory, Boulder, Colorado
}

(Manuscript received 8 September 2003, in final form 24 November 2003)

\begin{abstract}
In certain circumstances, millimeter-wavelength Doppler radar velocity spectra can be used to estimate the microphysical composition of both phases of mixed-phase clouds. This distinction is possible when the cloud properties are such that they produce a bimodal Doppler velocity spectrum. Under these conditions, the Doppler spectrum moments of the distinct liquid and ice spectral modes may be computed independently and used to quantitatively derive properties of the liquid droplet and ice particle size distributions. Additionally, the cloud liquid spectral mode, which is a tracer for clear-air motions, can be used to estimate the vertical air motion and to correct estimates of ice particle fall speeds.

A mixed-phase cloud case study from the NASA Cirrus Regional Study of Tropical Anvils and Cloud LayersFlorida Area Cirrus Experiment (CRYSTAL-FACE) is used to illustrate this new retrieval approach. The case of interest occurred on 29 July 2002 when a supercooled liquid cloud layer based at $5 \mathrm{~km}$ AGL and precipitating ice crystals advected over a ground measurement site. Ground-based measurements from both 35- and 94-GHz radars revealed clear bimodal Doppler velocity spectra within this cloud layer. Profiles of radar reflectivity were computed independently from the liquid and ice spectral modes of the velocity spectra. Empirical reflectivitybased relationships were then used to derive profiles of both liquid and ice microphysical parameters, such as water content and particle size. Although the ice crystals extended down to a height of $4 \mathrm{~km}$, the radar measurements were able to distinguish the base of the cloud liquid at $5 \mathrm{~km}$, in good agreement with cloud-base measurements from a collocated micropulse lidar. Furthermore, radar-derived cloud liquid water paths were in good agreement with liquid water paths derived from a collocated microwave radiometer.

Results presented here demonstrate the ability of the radar to both identify and quantify the presence of both phases in some mixed-phase clouds. They also demonstrate that, in terms of radar reflectivity, the ice component of mixed-phase clouds typically dominates the radar signal, while in terms of mean Doppler velocity, the liquid component can make a significant contribution. The high temporal resolution, 94-GHz Doppler radar observations were able to reveal a periodic cloud-top updraft that, combined with horizontal wind speeds, suggests a horizontal scale for the in-cloud circulations.
\end{abstract}

\section{Introduction}

Millimeter-wavelength Doppler radar spectra contain a wealth of information on cloud properties. The Doppler spectrum is the distribution of hydrometeor radial velocities, weighted by backscatter cross section, with respect to the radar antenna. It is thus a convolution of hydrometeor fall speeds and turbulence combined with air motions. For typical, operational radar observations, due to processing speed and data storage limitations,

Corresponding author address: Matthew Shupe, NOAA/Environmental Technology Laboratory, ET6, 325 Broadway, Boulder, CO 80305.

E-mail: Matthew.Shupe@noaa.gov the moments of the Doppler spectrum are computed and stored while the full Doppler spectrum is discarded. Therefore, radar-based cloud retrievals most often use only the zeroth or first moments of the Doppler spectrum-reflectivity and mean Doppler velocity-to derive quantities such as cloud water content and particle characteristic size (e.g., Matrosov et al. 1992; Liao and Sassen 1994; Frisch et al. 1995). When using only the moments of the Doppler spectrum, important spectral information can be lost, particularly when the spectrum is multimodal. Multimodal Doppler spectra can be caused by multiple, distinct drop/particle size distributions, by Mie backscattering oscillations with size (Kollias et al. 2002), and by variability in the air motion in 
a given radar pulse volume (Lhermitte 2002, p. 263) For example, the large differences in size distributions and fall regimes between the liquid droplets and ice crystals in a mixed-phase cloud often cause these two phases to fall at different velocities, thus producing a bimodal spectral signature.

Here, Doppler spectrum observations from vertically pointing, ground-based 35- and 94-GHz Doppler radars are used to identify and quantify the microphysical properties of both phases in a mixed-phase cloud. These unique measurements are also used to estimate the vertical air velocities encountered in these clouds. A case study on 29 July 2002 from the National Aeronautics and Space Administration's (NASA) Cirrus Regional Study of Tropical Anvils and Cirrus Layers-Florida Area Cirrus Experiment (CRYSTAL-FACE) is used to illustrate these methods. The case of interest occurred from 1500 to 1530 UTC when a supercooled altostratus layer based at $5 \mathrm{~km}$ above ground level (AGL) advected over a ground measurement site. Elevated concentrations of Saharan dust, an ice forming nucleus (DeMott et al. 2003), during this time period may have enhanced the growth of ice crystals from the supercooled liquid layer (Sassen et al. 2003).

The methods presented here suggest a new means for studying and monitoring mixed-phase clouds. Although mixed-phase clouds play an important role in global climate and aircraft safety, they are not well understood. The identification and partitioning of phases in mixedphase clouds is particularly difficult and has powerful implications in terms of the atmospheric and surface radiative balances (e.g., Sun and Shine 1994; Shupe and Intrieri 2004). In the Arctic, mixed-phase clouds are frequent $[\sim 41 \%$ of the time; Shupe et al. (2003, manuscript submitted to J. Appl. Meteor.).], and changes in Arctic mixed-phase cloud composition and/or fraction are expected to strongly impact the surface energy balance in that region. In midlatitudes, where mixed-phase clouds occur at higher altitudes and are somewhat less frequent than in the Arctic, supercooled liquid drops are a particularly important consideration for aircraft icing hazard conditions (Cober et al. 2001). In general, there is only limited knowledge of mixed-phase cloud structure and formation/persistence mechanisms, which has caused these clouds to be poorly represented in cloud and climate models (e.g., Morrison et al. 2003; Gregory and Morris 1996; Hogan et al. 2003). New observations and analysis methods for mixed-phase clouds will greatly improve our understanding of this widely important cloud type.

\section{Measurements}

All remote sensor measurements discussed here were made by ground-based instruments at the CRYSTALFACE eastern ground site located in Miami, Florida $\left(25^{\circ} 39^{\prime} \mathrm{N}, 80^{\circ} 26^{\prime} \mathrm{W}\right)$ on 29 July 2002 . The ground instrument site was designed to continuously monitor the
TABLE 1. Radar operational parameters. The sample interval for the $\mathrm{K}_{a}$-band radar is long because it cycles through a sequence of four operational modes. Characteristics labeled with an asterisk are for the specific $35-\mathrm{GHz}$ operational mode utilized here.

\begin{tabular}{lcc}
\hline \multicolumn{1}{c}{ Characteristic } & $\mathrm{K}_{a}$ band & W band \\
\hline Frequency & $34.86 \mathrm{Ghz}$ & $94.0 \mathrm{Ghz}$ \\
Wavelength & $8.6 \mathrm{~mm}$ & $3.2 \mathrm{~mm}$ \\
Antenna diameter & $1.8 \mathrm{~m}$ & 0.9 \\
Beamwidth & $0.3^{\circ}$, circular & $0.24^{\circ}$ \\
Peak power & $100 \mathrm{~W}$ & $1 \mathrm{~kW}$ \\
Sample time* & $1.8 \mathrm{~s}$ & $0.8 \mathrm{~s}$ \\
Sample interval* & $35 \mathrm{~s}$ & $3 \mathrm{~s}$ \\
Vertical resolution* & $45 \mathrm{~m}$ & $30 \mathrm{~m}$ \\
Sensitivity* & $-28 \mathrm{dBZ}$ at $5 \mathrm{~km}$ & $-35 \mathrm{dBZ}$ at $5 \mathrm{~km}$ \\
Coherent averages* & 4 & N/A \\
\hline
\end{tabular}

evolution of cloudiness in the region and to provide ground support for intensive observations made by six aircraft.

Measurements of the Doppler radar spectrum were made by a vertically pointing, 35-GHz, 8.66-millimeterwavelength cloud radar (MMCR; Moran et al. 1998) and a 94-GHz, 3.2-millimeter-wavelength cloud radar (Albrecht et al. 1999). All 35-GHz spectra used here are from one of four alternating operational modes that were used for this experiment [Clothiaux et al. (1999) discuss the basic MMCR operational modes]. This mode has 45-m vertical resolution, $\sim 35 \mathrm{~s}$ temporal resolution, and resolves the Doppler spectrum over the range of -4.1 to $+4.1 \mathrm{~m} \mathrm{~s}^{-1}$ in increments of $0.064 \mathrm{~m} \mathrm{~s}^{-1}$ using 128 fast Fourier transform (FFT) points. Each Doppler spectrum is an average over the radar's 1.8-s sample time. The 94-GHz Doppler spectra were measured at 30-m vertical resolution, $\sim 3$ s temporal resolution, and resolved the Doppler spectrum over the range of -4 to $+4 \mathrm{~m} \mathrm{~s}^{-1}$ in increments of $0.016 \mathrm{~m} \mathrm{~s}^{-1}$ using 512 FFT points. Each $94-\mathrm{GHz}$ spectrum is based on an average over the radar's 0.8-s sample time. Additional operational parameters pertaining to the radar measurements are summarized in Table 1. For typical cloud particle sizes $(<1 \mathrm{~mm})$, both radars will have little contribution from non-Rayleigh scattering except for the $94-\mathrm{GHz}$ radar signal from the largest ice crystals. An example 35-GHz Doppler spectrum is shown in Fig. 1, revealing a distribution of cloud particle relative motions that range from near zero to falling at over $2 \mathrm{~m} \mathrm{~s}^{-1}$ (positive velocities are downward). The first three moments of the Doppler spectrum are the reflectivity (proportional to the signal mean power), mean Doppler velocity (reflectivity-weighted mean velocity), and Doppler spectrum variance (the square root of which is called the spectrum width). These moments are typically calculated on an operational basis from measured Doppler spectra using the standard method, which identifies only the strongest continuous peak above the noise and does not distinguish multimodal spectra. For the half-hourlong 29 July case, the first three $35-\mathrm{GHz}$ radar moments calculated using the standard method (Fig. 2) show a 


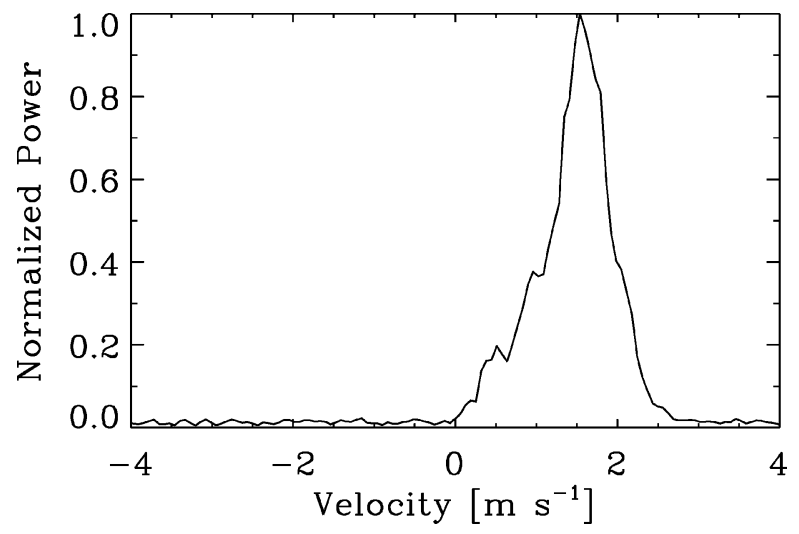

FIG. 1. An example normalized 35-GHz radar Doppler spectrum.

stratiform cloud layer that varies in thickness from 1.5 to $2 \mathrm{~km}$ with a substantial amount of in-cloud structure revealed in each moment.

Observations of backscatter from a collocated 523nm micropulse lidar (MPL; Campbell et al. 2002) are used to identify the base height of the liquid cloud layer. Since liquid cloud droplets typically occur in higher number concentrations, and therefore have a larger total cross-sectional area than ice cloud particles, the lidar backscatter is significantly stronger in cloud liquid than in cloud ice (e.g., Hogan et al. 2003). This difference in backscatter allows for the clear identification of the liquid cloud base for the 29 July case (plotted in Figs. $2 \mathrm{a}-\mathrm{c})$.

Downwelling brightness temperature observations at 20.6 and $31.65 \mathrm{GHz}$ from a collocated, vertically pointing microwave radiometer (MWR) are used to derive the column-integrated condensed liquid water path (LWP) with an uncertainty of about $25 \mathrm{~g} \mathrm{~m}^{-2}$ (Westwater et al. 2001). The time series of LWP for the 29 July case is shown in Fig. 2d, indicating that a substantial and variable amount of liquid water was present within the cloud layer.

Radiosonde temperature and wind speed profiles from the nearby Miami International Airport are used to confirm subfreezing temperatures within the cloud layer and to estimate the cloud advection. For the 29 July case, the $0^{\circ} \mathrm{C}$ isotherm was at $4 \mathrm{~km}$ and the temperature near cloud top at $6 \mathrm{~km}$ was $-11^{\circ} \mathrm{C}$. The wind speed at $5 \mathrm{~km}$ was $17 \mathrm{~m} \mathrm{~s}^{-1}$ at a direction of $115^{\circ}$.

\section{The 29 July mixed-phase Doppler spectra}

From a radar-moment-based perspective, the increase in Doppler spectrum width (the square root of the second moment) with height in the 29 July case (Fig. 2c) suggests that the details of the Doppler spectra contain more information on the cloud microphysical properties than is available from the radar moments alone. Figure 3 shows 35-GHz Doppler spectra at six heights within the cloud layer at 1508 UTC (the 94-GHz Doppler spectra are similar). These spectra reveal distinct spectral signatures from both cloud liquid and ice. Near cloud top the spectra are clearly broad and bimodal, a feature that causes the wide spectral widths observed in this region (Fig. 2c). These observations suggest that in certain circumstances (i.e., negligible turbulent broadening), the Doppler spectrum width is useful for identifying mixedphase cloud conditions.

The spectral mode at negative (ascending) Doppler velocities in Fig. 3 indicates the presence of liquid droplets and an updraft. A cloud-top updraft of this nature has been shown to be crucial for liquid formation and persistence in mixed-phase clouds (e.g., Rauber and Tokay 1991; Harrington et al. 1999). Descending through the cloud layer, the liquid spectral mode decreases in relative magnitude and disappears altogether below about $5 \mathrm{~km}$. The second spectral mode, showing stronger downward fall speeds that indicate larger ice particles, increases in relative importance with descending depth in the cloud and is the only spectral mode observed below $5 \mathrm{~km}$ in the cloud layer. In this example profile, the radar signal from the cloud liquid dominates the total signal near the cloud top, a feature that was not common in this case study.

An alternate way to examine the Doppler spectrum, in a topographic manner with height, is provided in Fig. 4. This spectrograph reveals the location and evolution with height of the two spectral modes discussed above. The strongest returns in the ice spectral region, which indicate the largest ice particles, are located below the base of the cloud liquid. Below $4.5 \mathrm{~km}$ the relative decrease in reflectivity indicates that the ice particles are decreasing in size and/or concentration. The sharp increase in fall speeds just below $4 \mathrm{~km}$ (the $0^{\circ} \mathrm{C}$ isotherm) indicates a melting of the remaining ice particles into raindrops, which fall quickly before evaporating.

In summary, the Doppler spectra indicate that ice occurs throughout the depth of this cloud layer and that liquid exists only in the top portion of the cloud. The spectra also suggest an updraft in the upper portion of the cloud. Supporting observations from the microwave radiometer confirm the presence of the liquid water, while observations from the MPL confirm that the base of the liquid is somewhat higher than the cloud base observed by the radar (Fig. 2a). This general mixedphase cloud structure is similar to other mixed-phase clouds observed by aircraft (e.g., Hobbs and Rangno 1985; Pinto 1998), observed by remote sensors (Hogan et al. 2003), and modeled (Rauber and Tokay 1991; Harrington et al. 1999).

\section{Spectral processing and retrieval methods}

The two distinct spectral modes observed in the 29 July mixed-phase cloud can provide quantitative information on both the cloud liquid and ice microphysical properties. Additionally, the location of the cloud liquid spectral peak can be used to estimate the vertical air 


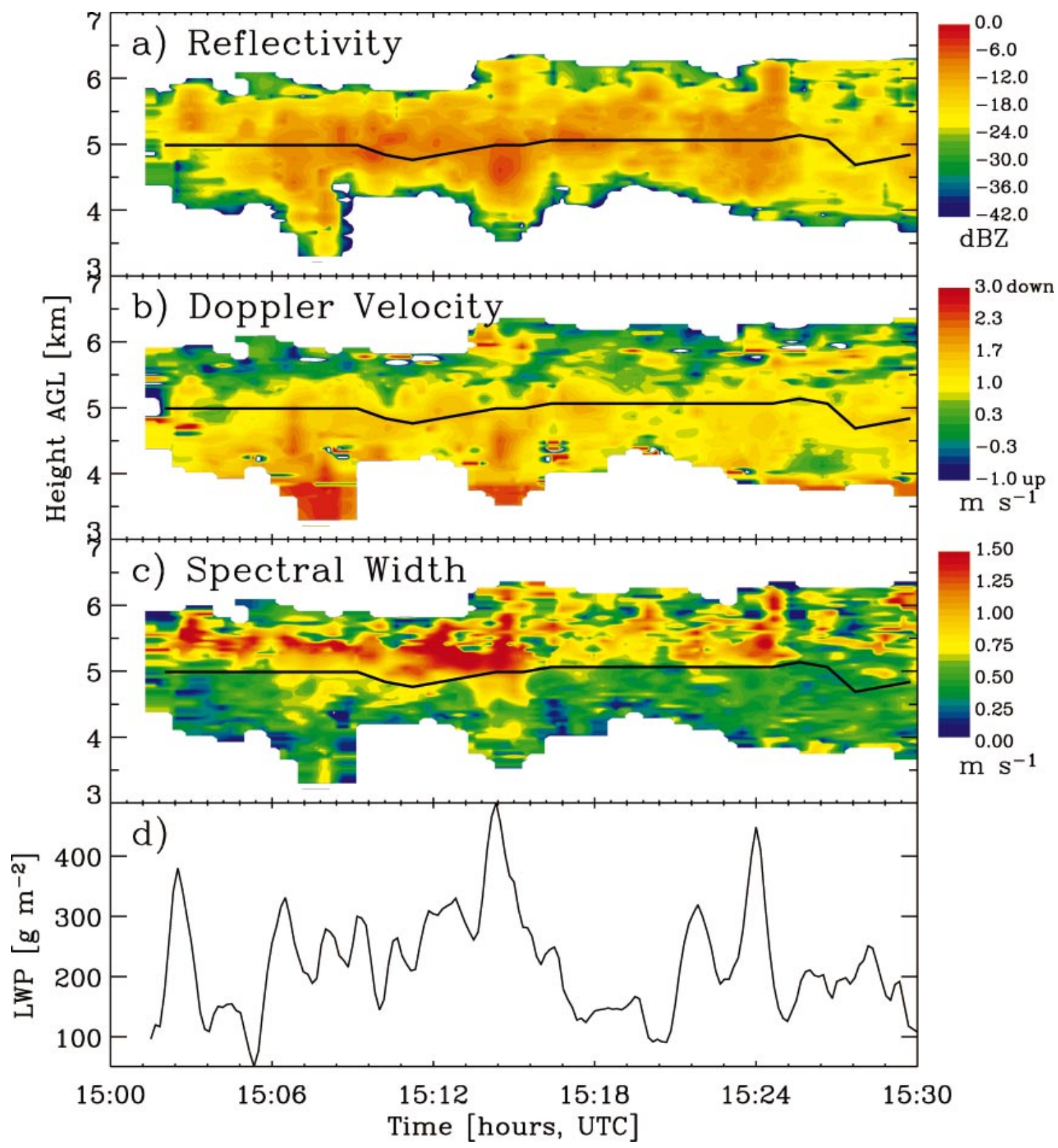

FIG. 2. Time-height contours of 35-GHz, total Doppler spectrum (a) radar reflectivity, (b) mean Doppler velocity, (c) Doppler spectrum width, and (d) a time series of microwave-radiometer-derived LWP for the $29 \mathrm{Jul}$ case study. The micropulse lidar liquid cloud base is overplotted as a thin black line in (a)-(c).

motion. In the following section, the spectral processing and retrieval techniques will be specifically discussed for the 35-GHz Doppler radar measurements; however, a similar method was also applied to the $94-\mathrm{GHz}$ measurements.

\section{a. Spectral processing}

All 35-GHz Doppler spectra are smoothed using a three-point $\left(0.192 \mathrm{~m} \mathrm{~s}^{-1}\right.$ wide) boxcar averaging window to improve spectral clarity. For all smoothed spec- tra, the spectral noise level is computed using the Hildebrand and Sekhon (1974) method. According to this method, the highest spectral points are removed one by one until the remaining spectral points have the characteristics of a Gaussian noise distribution. From these remaining points, the mean and standard deviation of the noise are then calculated. The MMCR noise level is typically quite stable in time, not varying by more than about $0.5 \mathrm{dBZ} \mathrm{day}^{-1}$ (K. P. Moran 2003, personal communication).

A spectral peak-picking algorithm is then applied to 


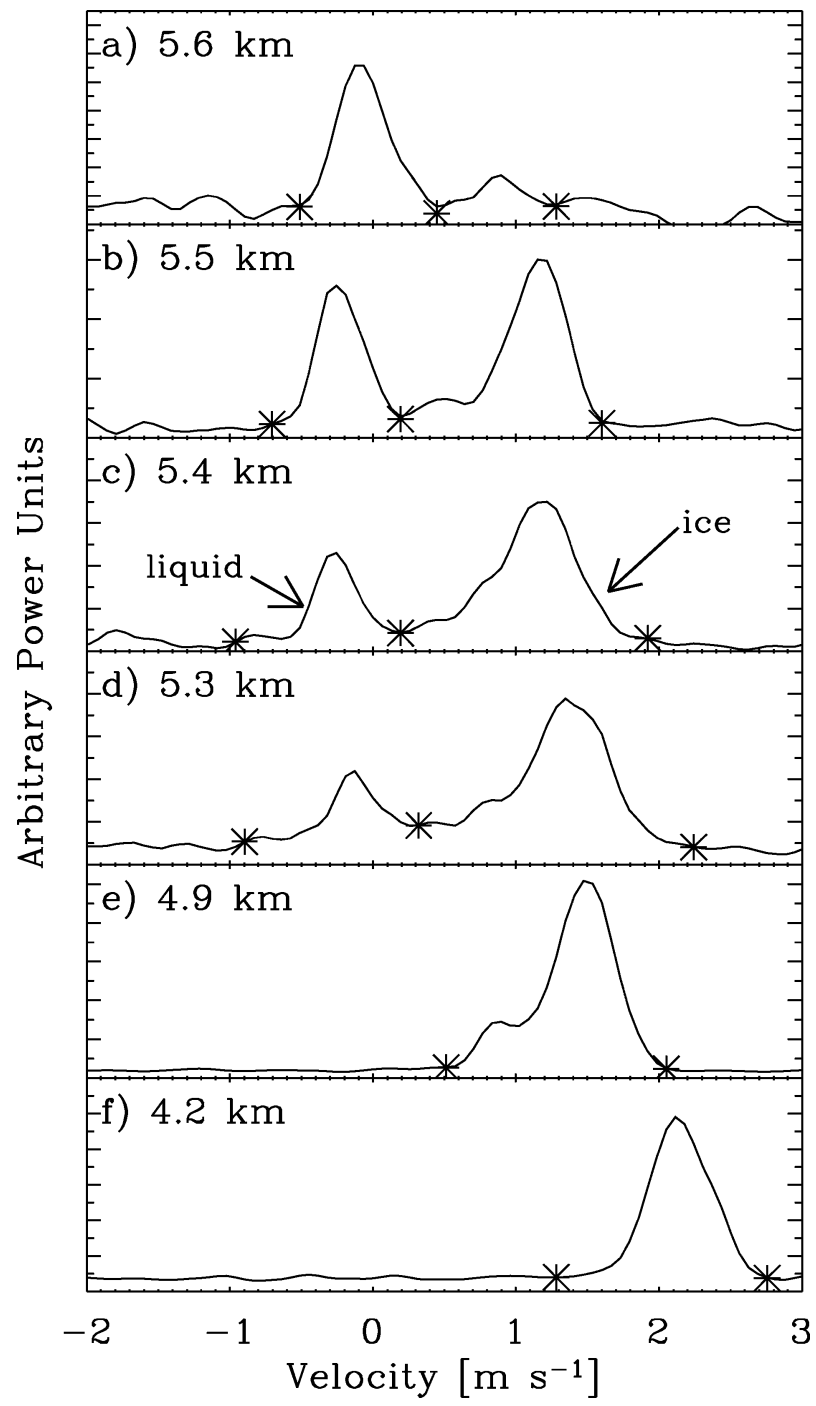

FIG. 3. The 35-GHz radar Doppler spectra at six heights in the 29 Jul case study at 1508 UTC. The boundaries of the spectral modes are designated by stars.

identify the significant spectral modes according to the following criteria.

1) The primary (or strongest) peaks must be at least 4 standard deviations of the noise greater than the spectral noise level.

2) All secondary peaks must be at least 2.5 standard deviations of the noise greater than the spectral noise level.

3) Any spectral mode must have a width of at least $0.448 \mathrm{~m} \mathrm{~s}^{-1}$ (or seven continuous $35-\mathrm{GHz}$ velocity bins) above the noise level.

4) For two continuous modes above the noise to be considered distinct modes, the saddle point between the peaks must be lower than $65 \%$ of the lowest of the two peaks from the noise level.

The peak-picking criteria used in this case were de- termined empirically by manual inspection of the peakpicking results. All criteria were adjusted to maximize the algorithm's ability to correctly identify the major spectral features. The algorithm correctly determined the major peaks in about $90 \%$ of the nearly 180035 $\mathrm{GHz}$ spectra in this case and made only minor errors, with a few exceptions, in particularly noisy or nonuniform spectra. Due to the uniqueness of each Doppler spectrum, there is no clear manner to quantify the errors caused by incorrect peak classification.

Once spectral peaks are identified, the boundaries of spectral modes are determined by descending from each peak in both directions until either the noise level or an identified saddle point is reached. For the purposes of this mixed-phase cloud case, only two modes were allowed: the mode with the greatest fall speeds was assigned to be ice and the mode with the smallest fall speeds was assigned to be liquid. Based on the specific nature of this case (cloud liquid was typically not observed without cloud ice), if only one spectral mode was identified, it was assumed to indicate cloud ice. The boundaries of the distinct liquid and ice $35-\mathrm{GHz}$ spectral modes determined using this algorithm are indicated by stars in Fig. 3. When a boundary between two modes was defined by a saddle point, the split was simply made at the saddle point velocity bin. No attempt was made to extrapolate either mode into the velocity range of the other mode, as was done by Gossard et al. (1997), because the spectra did not suggest a clear and consistent manner in which to do so. The overall effect of the saddle point splitting is to transfer a small portion of the total power from the dominant mode into the less dominant mode. For example, in the spectrum shown in Fig. 3d, a small portion of the total power is incorrectly associated with the cloud liquid spectral mode that should be associated with the cloud ice spectral mode. Another source of error may occur if the two spectral modes are not sufficiently distinct to fulfill the peak-picking criteria-an error that is most likely to occur at very low levels of cloud liquid or when ice crystal sizes are small (or similar in size to the liquid droplets). Under these circumstances, only one spectral mode, which is assumed to be ice, will be identified, causing a bias error in the cloud liquid retrievals. Once the spectral modes have been identified and distinguished by phase, the moments (reflectivity and mean Doppler velocity) of each mode are calculated.

A similar spectral processing algorithm was applied to the higher temporal, vertical, and spectral resolution 94-GHz spectra. The $94-\mathrm{GHz}$ spectra were smoothed with an 11-point $\left(0.176 \mathrm{~m} \mathrm{~s}^{-1}\right.$ wide) boxcar smoothing window. Peak-picking criteria similar to those discussed above were applied to the smoothed, calibrated $94-\mathrm{GHz}$ spectra. Due to the shorter sampling time for the 94$\mathrm{GHz}$ measurements, spectral features were typically narrower; therefore, a threshold of two standard deviations above the noise was sufficient to distinguish the spectral peaks in these measurements. It is important to note that 


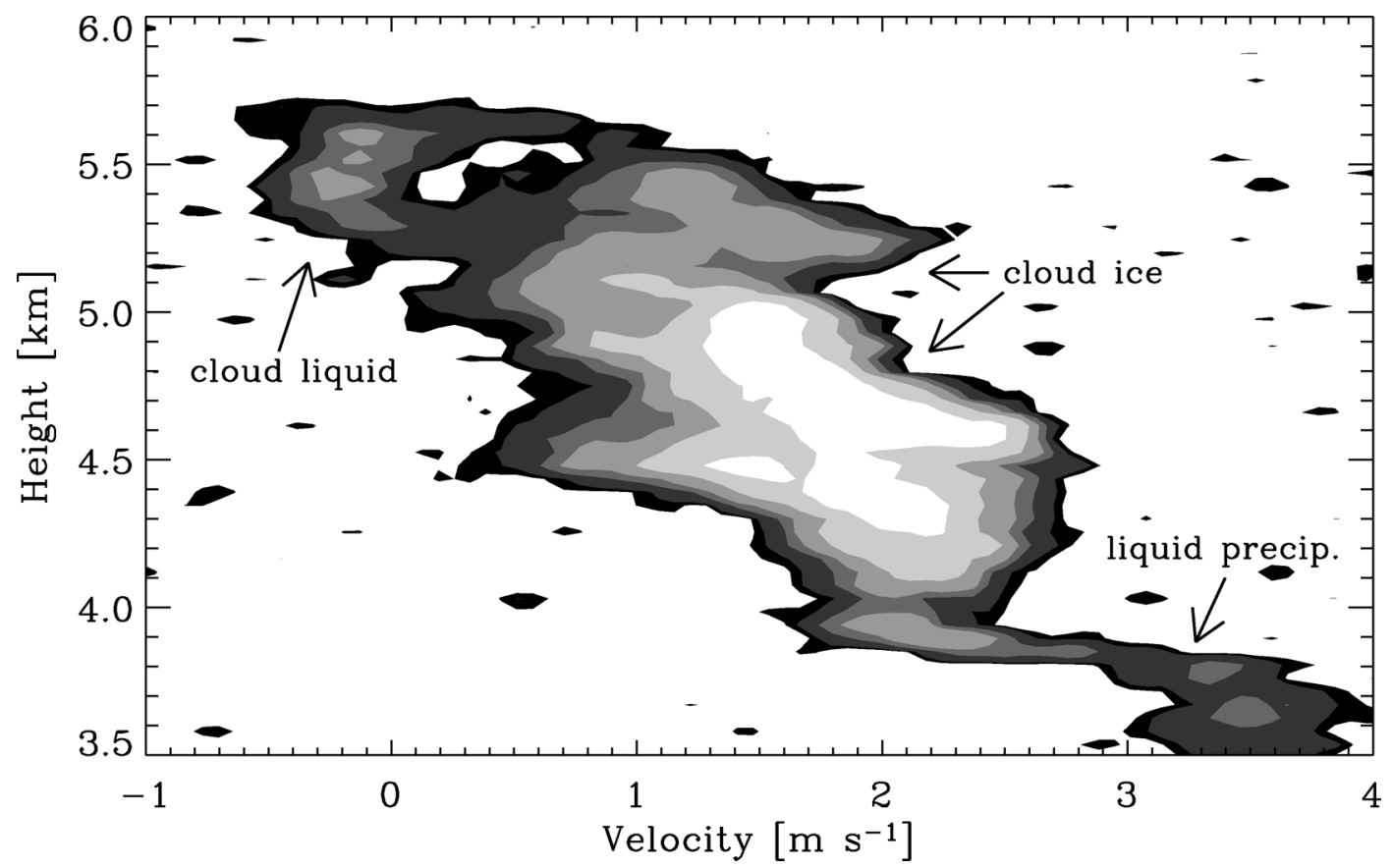

FIG. 4. Velocity vs height spectrograph from the $35-\mathrm{GHz}$ radar at 1508 UTC on 29 Jul. Contours indicate relative power, with increasing power indicated by lighter hues.

the peak-picking criteria will likely require further adjustment for different mixed-phase cloud cases and/or for radar measurements made at different wavelengths and sampling parameters.

\section{b. Estimating vertical air motions}

The terminal fall velocity of cloud liquid droplets is typically negligible compared to vertical air motions; the Stokes terminal fall velocity for a $10-\mu \mathrm{m}$-radius liquid drop is less than $1 \mathrm{~cm} \mathrm{~s}^{-1}$. Thus, cloud droplets can be considered as tracers for the air motion (e.g., Gossard et al. 1997; Babb et al. 1999; Kollias et al. 2001). When a cloud liquid spectral mode is identified in a given Doppler spectrum, the mean vertical air motion is estimated from the offset of the cloud liquid spectral peak from $0 \mathrm{~m} \mathrm{~s}^{-1}$. Vertical air motions derived in this manner can then be used to correct the ice particle fall speeds calculated from the ice spectral mode to provide more accurate estimates of ice particle terminal fall velocities. When a distinct liquid spectral mode is not present, this type of ice fall speed correction is not possible.

\section{c. Cloud microphysics retrievals}

Using the computed profiles of reflectivity and/or mean Doppler velocity, various moment-based microphysics retrieval methods can be applied to the liquid and ice spectral modes separately. In this work, as an example, reflectivity power law regressions are used to relate $35-\mathrm{GHz}$ radar reflectivity $\left(Z_{e}\right.$, in $\left.\mathrm{mm}^{6} \mathrm{~m}^{-3}\right)$ to cloud microphysical parameters. Retrievals of this type have been widely applied to single-phase clouds in the past; therefore, the following will only briefly summarize the specifics of how these retrievals are applied in this case.

For an assumed lognormal droplet size distribution, relationships between reflectivity and liquid water content ( $\mathrm{LWC}$, in $\left.\mathrm{g} \mathrm{m}^{-3}\right)$ and droplet effective radius $\left(R_{e}\right.$, in $\mu \mathrm{m}$ ) have the forms (Frisch et al. 1995, 2002)

$$
\begin{aligned}
\mathrm{LWC} & =(\pi / 6) \rho \exp \left(-4.5 \sigma^{2}\right) N^{1 / 2} Z_{e}^{1 / 2} \text { and } \\
R_{e} & =50 \exp \left(-0.5 \sigma^{2}\right) N^{-1 / 6} Z_{e}^{1 / 6}
\end{aligned}
$$

respectively, where $\rho$ is the density of water, $\sigma=0.31$ is the assumed logarithmic spread of the droplet size distribution, and $N$ is the droplet number concentration $\left(\mathrm{cm}^{-3}\right)$. Both $\sigma$ and $N$ are assumed to be constant with height. A perusal of in situ measurements made by a forward scattering spectrometer probe flown on the University of North Dakota Citation research aircraft during CRYSTAL-FACE showed that typical liquid droplet concentrations in mixed-phase clouds during the experiment were about $25-35 \mathrm{~cm}^{-3}$. Therefore, a concentration of $35 \mathrm{~cm}^{-3}$ is used in (1) and (2), although it is somewhat lower than typical liquid droplet concentrations measured in a marine environment (e.g., Miles et al. 2000). Although the uncertainties of (1) and (2) when applied to mixed-phase clouds are unknown, the uncertainties in all-liquid clouds are about $50 \%$ for LWC (Fox and Illingworth 1997) and $13 \%$ for $R_{e}$ (Frisch et al. 2002). 


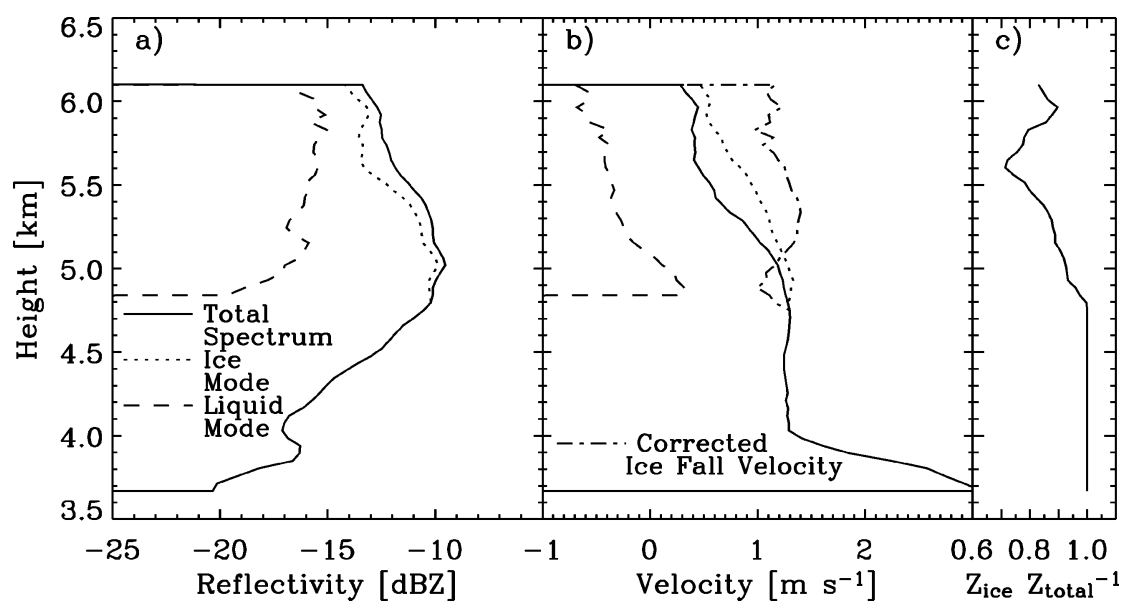

FIG. 5. Case-averaged profiles of 35-GHz (a) reflectivity and (b) mean Doppler velocity for the liquid-only spectral mode, the ice-only spectral mode, and the total Doppler spectrum. A corrected ice-only mean Doppler velocity profile is also plotted in (b). (c) The case-averaged ratio of ice-only reflectivity $\left(Z_{\text {ice }}\right)$ to total reflectivity $\left(Z_{\text {total }}\right)$ is given. Note that the average values at a given height are derived from all available observations at that height, the number of which varies with height.

Similar reflectivity-based retrievals are used to derive ice cloud microphysical properties. For ice water content (IWC, in $\mathrm{g} \mathrm{m}^{-3}$ ), an empirical regression of the form

$$
\mathrm{IWC}=a Z_{e}^{b}
$$

is applied to ice-only reflectivity profiles. Here values of $a=0.12$ and $b=0.63$ are assumed based on the results of Matrosov (1999). For an assumed particle bulk density-size relationship (Brown and Francis 1995) and an assumed exponential particle size distribution, $Z_{e}$ is a function of the characteristic ice particle size (e.g., the median volume size, $D_{o}$ ) and the IWC (Atlas et al. 1995). Thus, (3) can be used to estimate $D_{o}$ (in $\mu \mathrm{m}$ ) as

$$
D_{o}=143 a^{-0.526}\left(Z_{e}^{1-b}\right)^{0.526} \text {. }
$$

For the assumed exponential particle size distribution, the characteristic particle size can be converted into an effective radius according to Matrosov et al. (2003). The expected uncertainty for IWC and $D_{o}$ retrievals of this type is as high as a factor of 2 (Atlas et al. 1995; Liu and Illingworth 2000).

\section{Results and discussion}

\section{a. Radar moments}

Case-averaged profiles of $35-\mathrm{GHz}$ radar reflectivity and mean Doppler velocity, derived for the liquid and ice components of the 29 July mixed-phase cloud, are shown in Fig. 5. The profile of mean Doppler velocity derived from the liquid spectral mode suggests an updraft of up to $0.7 \mathrm{~m} \mathrm{~s}^{-1}$ near the top of the liquidcontaining cloud region. Using the updraft velocities estimated from the liquid spectral mode, the measured ice particle mean Doppler velocities were adjusted to provide an estimate of the ice particle fall speeds (Fig. $5 b$ ). The sharp increase in fall speed below $4 \mathrm{~km}$ (the $0^{\circ} \mathrm{C}$ isotherm) suggests that the cloud ice particles have melted into raindrops below this height. For comparison, the moments of the "total" 35-GHz Doppler spectrum calculated using the standard operational method (not distinguishing bimodalities) have also been plotted. These standard moments are what are typically calculated from operational radar data when the full Doppler spectrum is not retained. Note that the case-averaged profiles given in Fig. 5 are based on all available observations at a given height. Cloud ice was observed through the duration of the case at nearly all heights; however, cloud liquid occurred less frequently at some heights. Therefore, the average liquid profiles are based on fewer observations.

The first notable result of this retrieval method is that, from the radar measurements alone, the base of the cloud liquid can be accurately identified at about $5 \mathrm{~km}$. The 35-GHz radar-determined liquid cloud base, or the lowest radar range gate with a bimodal Doppler spectrum, is compared to the MPL liquid cloud base in Fig. 6, showing excellent general agreement with differences typically less than $200 \mathrm{~m}$ at any given time. The caseaveraged cloud-base heights are 4.99 and $4.97 \mathrm{~km}$ for the radar and MPL, respectively.

Case-averaged profiles of the $94-\mathrm{GHz}$ radar moments (not shown) are qualitatively similar to the $35-\mathrm{GHz}$ profiles in Fig. 5. In general, the 94-GHz reflectivities are lower by about $2-3 \mathrm{dBZ}$ due to the higher atmospheric attenuation of the radar signal at this wavelength. Near cloud top, the mean Doppler velocities of the ice spectral mode derived from the 35- and $94-\mathrm{GHz}$ measurements are similar. However, as the ice particles grow and descend through the cloud layer, the $94-\mathrm{GHz}$ ice velocities 


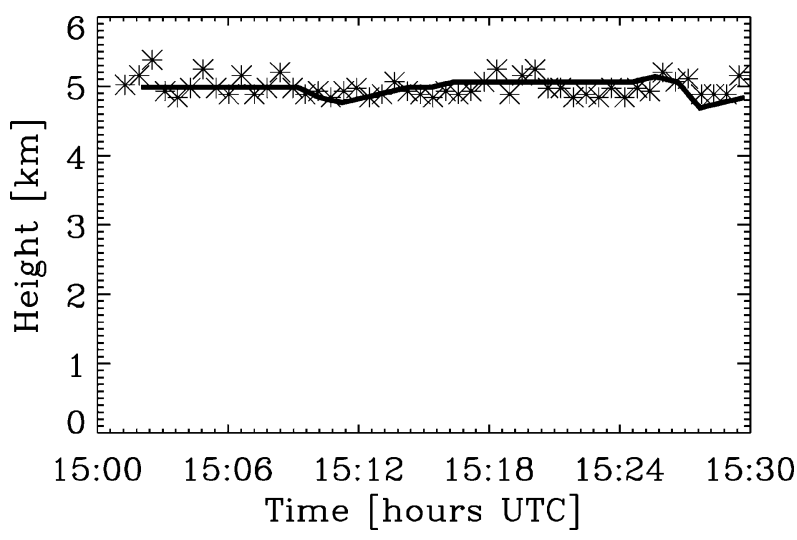

FIG. 6. Time series of micropulse-lidar-derived liquid cloud base height (line) and 35-GHz-radar-derived liquid cloud-base height (stars).

do not increase as much as the $35-\mathrm{GHz}$ ice velocities. This difference is likely due to the effect of non-Rayleigh scattering from the largest ice crystals on the 94$\mathrm{GHz}$ measurements, which effectively decreases the weighting of the largest and fastest falling particles.

\section{b. Cloud microphysical properties}

Profiles of LWC, IWC, and droplet and particle effective sizes, retrieved from the $35-\mathrm{GHz}$ measurements and averaged over the half-hour case study, are shown in Fig. 7. Cloud liquid forms just below $5 \mathrm{~km}$, steadily increases as the average updraft velocity increases up to a height of about $5.9 \mathrm{~km}$, and then slightly decreases up to the cloud top at $6.1 \mathrm{~km}$. Cloud ice, on the other hand, forms near cloud top and grows steadily as the ice particles fall through the region of supercooled liquid, reaching a maximum $I W C$ near the base of the cloud liquid. Case-averaged, column-integrated values of IWP, LWP, and water content-weighted, layer-averaged par-
TABLE 2. Case-averaged values of retrieved cloud liquid properties from the liquid-only spectral mode and the microwave radiometer, and retrieved cloud ice properties from the ice-only spectral mode and the total Doppler spectrum. Sizes are layer-averaged and water content weighted.

\begin{tabular}{lcc}
\hline \hline & LWP or IWP $\left(\mathrm{g} \mathrm{m}^{-2}\right)$ & $R_{e}(\mu \mathrm{m})$ \\
\hline Liquid mode & 184 & 14.2 \\
MWR & 219 & - \\
Ice mode & 32.7 & 49.3 \\
Total spectrum & 35.1 & 49.6 \\
\hline
\end{tabular}

ticle and droplet sizes are summarized in Table 2. A comparison of the average LWP that was independently derived from the collocated microwave radiometer (219 $\mathrm{g} \mathrm{m}^{-2}$ ) with the 35-GHz radar-based retrieval $(184 \mathrm{~g}$ $\mathrm{m}^{-2}$ ) reveals the notable result that the liquid component of this mixed-phase cloud can be quantified, with reasonable accuracy $(\sim 16 \%)$, from radar reflectivity measurements alone. In terms of point-to-point comparisons (Fig. 8), the radar retrievals were able to distinguish the major cloud liquid water features identified by the MWR but at times underpredicted the LWP. Most notably, the radar did not identify enough liquid water at 1502, 1507-1508, and 1525-1530 UTC. The shortcomings during these time periods were due to two sets of circumstances that reveal the major difficulties encountered when using this method. First, near the liquid cloud base where the LWC was relatively small, the liquid spectral peak was not sufficiently distinct from the spectral noise. Second, near the liquid cloud top where the ice crystals formed, the ice crystals were relatively small and the spectral features associated with the cloud liquid and ice in this region were at times indistinguishable and were therefore classified as ice only. In other words, the saddle point between peaks was, at times, not deep enough to fulfill the criterion. In addition to these shortcomings, the Doppler spectra

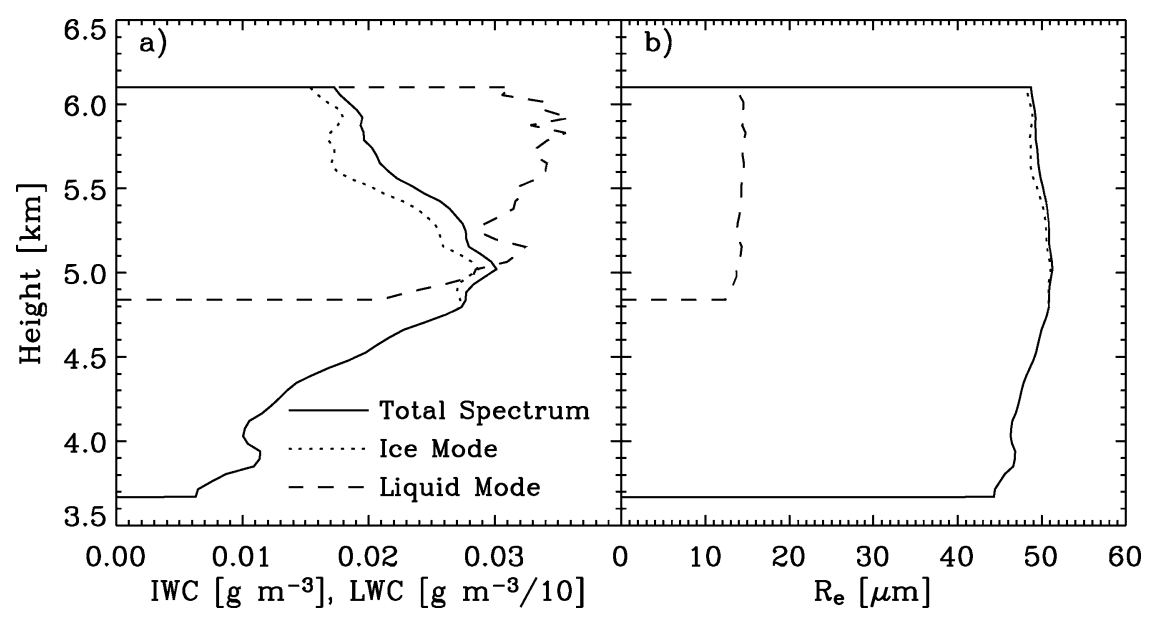

FIG. 7. Case-averaged profiles of $35-\mathrm{GHz}$ radar-derived (a) liquid and ice water content and (b) liquid droplet and ice particle effective radius. In each panel, ice properties derived from the total Doppler spectrum reflectivity are also plotted. 


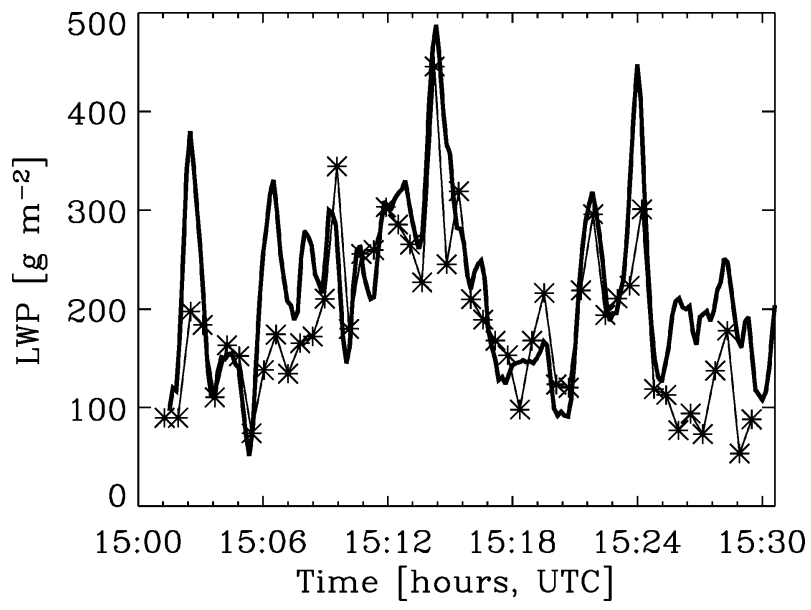

FIG. 8. Time series of the microwave-radiometer-derived LWP (thick line) and LWP derived from the $35-\mathrm{GHz}$ radar (stars).

from 1525 to 1530 UTC were less uniform and appeared to contain a lower signal-to-noise ratio than at other times, which hindered the spectral classification algorithm.

\section{c. Vertical air motions}

Vertical air motions were derived from both 35- and 94-GHz radar measurements. Due to their higher temporal resolution, the $94-\mathrm{GHz}$ measurements were able to resolve smaller-scale cloud vertical motions and circulations. An example 10-min time series of the 94GHz-derived vertical air motion averaged from 5.5 to $5.6 \mathrm{~km}$ AGL (Fig. 9b) reveals periodic updraft pulses. The mean updraft velocity over this time period is approximately $0.5 \mathrm{~m} \mathrm{~s}^{-1}$, which agrees with the average updraft at $5.6 \mathrm{~km}$ derived from the lower temporal resolution 35-GHz measurements (Fig. 5) and suggests large-scale lifting in the region. Over the course of this 10 -min period there are about seven or eight major updraft pulses that indicate the presence of cloud-scale circulations, and that coincide with increases in the MWR-derived LWP (Fig. 9a). The association between updrafts and the formation of liquid in mixed-phase clouds has been demonstrated in various model studies (e.g., Rauber and Tokay 1991; Harrington et al. 1999). Also of interest is the correlated response of the cloud ice to the updraft-induced liquid water formation, which has also been studied using models (Korolev and Isaac 2003). The relative ice particle fall velocities derived from the ice spectral mode (Fig. 9c) were corrected using the derived updraft velocities to provide estimates of the true ice particle fall velocities at 5.5-5.6 km (Fig. $9 \mathrm{~d})$. As the formation of cloud liquid increases during the updrafts, the ice particle fall velocities also increase, indicating the growth of ice particles at these times.

The apparent length scale of these cloud circulations, from the perspective of the vertically pointing instruments, is determined by the spatial changes in cloud-

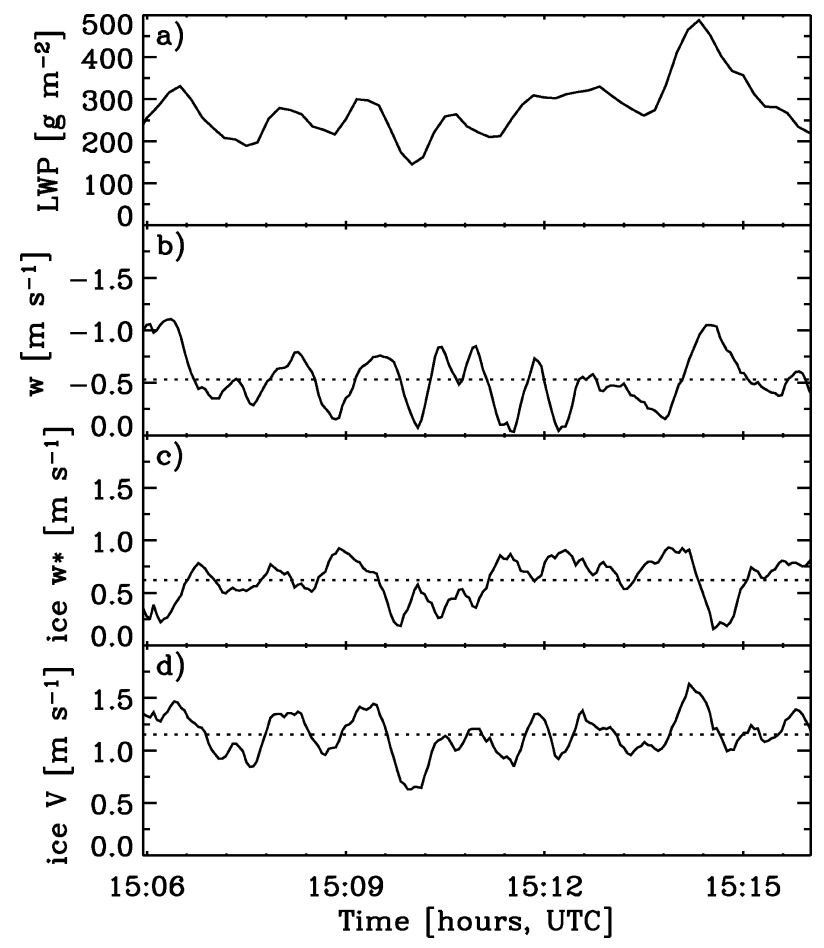

FIG. 9. Time series of (a) microwave-radiometer-derived LWP, (b) updraft velocity derived from the liquid spectral mode, (c) relative ice particle fall speed derived from the ice spectral mode, and (d) corrected ice particle fall velocities (relative ice fall speed plus the updraft velocity). The velocities in (b)-(d) were derived from 94$\mathrm{GHz}$ measurements and averaged over the height range of 5.5-5.6 $\mathrm{km}$. Horizontal dashed lines indicate mean parameter values over the time period of interest.

scale circulations with respect to the moving cloud parcel combined with the advection of the parcel itself. If the circulations are assumed to be static with respect to the cloud parcel (i.e., only considering the cloud advection), then an estimate of the horizontal length scale of cloud circulations can be made. The mean wind speed at $5.6 \mathrm{~km}$ during the 1500 UTC sounding was about 17 $\mathrm{m} \mathrm{s}^{-1}$. Since there were seven or eight circulations in the 10-min period, this implies a horizontal length scale of about $1300-1400 \mathrm{~m}$ for the in-cloud circulations. Consequently, the ratio of the horizontal length scale to the vertical liquid cloud depth is approximately 1.3:1, which is near the typical aspect ratio of Rayleigh-Benard cellular convection in altostratus clouds (Houze 1993, p. 193). Furthermore, by subtracting the mean, large-scale vertical lifting of $0.5 \mathrm{~m} \mathrm{~s}^{-1}$, these observations reveal that the cloud-scale circulations are characterized by relative up- and downdrafts of $\pm 0.5 \mathrm{~m} \mathrm{~s}^{-1}$ at the $5.6-\mathrm{km}$ height.

\section{d. Ice dominance of the radar signal}

Due to size considerations, it may be reasonable to assume that the large ice particles in a mixed-phase cloud dominate the radar signal (which nominally re- 
sponds to hydrometeor size to the sixth power). Under this assumption, if full Doppler spectra measurements are not available, ice retrievals might be applied to the total spectrum moments, which are calculated using the standard operational method, in order to characterize only the ice component of these clouds. To test this hypothesis, the total spectrum moments (see Fig. 5) are assumed to characterize the ice component only and are compared to the moments from the individual ice spectral mode.

Although there are a few counterexamples (i.e., Figs. $3 \mathrm{a}$ and $3 \mathrm{~b}$ ), the cloud ice component does, on average, dominate the $35-\mathrm{GHz}$ radar signal through the depth of this cloud, accounting for an average of $70 \%-100 \%$ of the total reflectivity (Fig. 5c). Where liquid is present near cloud top, the reflectivity from the ice spectral mode is on average $\sim 1 \mathrm{dBZ}$ less than the total reflectivity observed by the radar (Fig. 5a). This difference is similar to the uncertainty of the reflectivity measurements themselves $(\sim 1 \mathrm{dBZ})$. Thus, the assumption that the ice component of this mixed-phase cloud dominates the radar reflectivity is reasonable. For the reflectivitybased ice retrievals given in section $4 c$, if the total radar reflectivity were assumed to come entirely from the ice, the IWP in this case would be overestimated by about $7 \%$ and the layer-mean retrieved ice particle effective radius would be overestimated by less than $1 \%$ with respect to the ice-only spectral mode retrievals (see Table 2).

In terms of the mean Doppler velocity, however, the contributions from the liquid component and the vertical air motion are important and bias the ice particle fall velocities. As indicated in Fig. 5b, the ice component in the upper portion of the cloud is falling approximately $0.2-0.4 \mathrm{~m} \mathrm{~s}^{-1}$ faster than the total spectrum mean velocity. Furthermore, the liquid spectral mode suggests that there is a $0.4 \mathrm{~m} \mathrm{~s}^{-1}$ average updraft above $5 \mathrm{~km}$ in the cloud. Thus, the actual ice fall speeds above $5 \mathrm{~km}$ are significantly larger than would be expected if the ice component were assumed to dominate the total spectrum mean Doppler velocity. Corrected ice particle fall velocities of this nature allow for the more accurate use of ice retrievals based on fall velocity-size relationships (Matrosov et al. 2002; Mace et al. 2002) in mixed-phase clouds.

\section{Conclusions}

An altostratus cloud case on 29 July 2002 from the CRYSTAL-FACE experiment is used to demonstrate an approach to derive cloud microphysical properties for both liquid and ice components of mixed-phase clouds from millimeter-wavelength Doppler radar spectra. Bimodal Doppler spectra can occur when significant amounts of cloud liquid and ice simultaneously exist in a mixed-phase cloud. In this study, the separation of bimodal spectral peaks was sufficient to allow for the distinction of the spectral modes by phase. This case also demonstrates the utility of the Doppler spectrum width for identifying the presence of these mixed-phase bimodal spectra. After computing the radar moments for each spectral mode separately, cloud microphysics retrievals were applied to characterize both cloud phases.

The analysis presented here demonstrates the ability of the radar to distinguish the presence of mixed-phase cloud liquid and ice, to identify the vertical location of each phase, and to quantify the microphysical properties of each phase. Additionally, by assuming that the cloud liquid is a tracer for the air motion, the vertical air motion can be derived and used to correct ice particle fall velocities. This analysis also suggests that high temporal resolution estimates of the vertical air motion can reveal important information on the strength and characteristic length scales of cloud-scale circulations.

A comparison of the Doppler moments of the iceonly spectral mode with the standard moments of the total Doppler spectrum (not distinguishing bimodalities) shows that the ice component of mixed-phase clouds typically dominates the total radar reflectivity but that the cloud liquid and vertical air motion make significant contributions to the total mean Doppler velocity, which biases the derivation of ice particle fall speeds. Thus, in the absence of Doppler spectra, the ice component of mixed-phase clouds can be derived, with a reasonable amount of certainty, from radar reflectivity measurements alone and with much less certainty from Doppler velocity measurements. As the mixed-phase cloud liquid water amount decreases, the ice dominance of the radar signal becomes stronger (making moment-based ice retrievals more accurate) and the radar's ability to identify and quantify the liquid component decreases. Furthermore, under certain circumstances the distinction between liquid droplets and small ice crystals in mixedphase clouds is not possible using millimeter Doppler radars.

This new method for analyzing radar Doppler spectra motivates the processing and storage of full Doppler spectra during routine radar operations. It also suggests that more robust peak-picking algorithms that are capable of identifying multimodal spectra are needed for operational radar systems. Additionally, this work demonstrates the value of high temporal resolution radar measurements for studying cloud-scale motions and processes. Similar Doppler spectrum analysis methods may be useful for distinguishing the contributions to the radar signal from cloud liquid and drizzle drops (e.g., Gossard et al. 1997), for retrieving information on the ice and/ or liquid size distributions (e.g., Babb et al. 1999), for distinguishing the properties and processes associated with different ice particle habits, and for studying the role of cloud-scale circulations and vertical motions in mixed-phase cloud evolution and persistence. In addition to these climate research applications, the ability of this method to identify altitudes containing supercooled liquid water suggests applications with regard to aircraft icing and cloud seeding. 
Acknowledgments. This research was supported by the NASA Radiation Sciences program. Micropulse lidar observations were made under the direction of SiChee Tsay and E. Judd Welton and data were obtained from the MPLNET Web site (mplnet.gsfc.nasa.gov). Aircraft observations from the University of North Dakota Citation research aircraft were obtained from Micheal Poellot. Comments from two anonymous reviewers are much appreciated. Thanks to Duane Hazen, Ken Moran, Taneil Uttal, Bruce Albrecht, and Vic Delnore.

\section{REFERENCES}

Albrecht, B. A., P. Kollias, R. Lhermitte, and R. Peters, 1999: Observations of tropical cloud systems with a mm-wavelength Doppler radar-An overview. Preprints, 29th Int. Conf. on Radar Meteorology, Montreal, QC, Canada, Amer. Meteor. Soc., 454456.

Atlas, D., S. Y. Matrosov, A. J. Heymsfield, M.-D. Chou, and D. B. Wolff, 1995: Radar and radiation properties of ice clouds. $J$. Appl. Meteor., 34, 2329-2345.

Babb, D. M., J. Verlinde, and B. A. Albrecht, 1999: Retrieval of cloud microphysical parameters from $94-\mathrm{GHz}$ radar Doppler power spectra. J. Atmos. Oceanic Technol., 16, 489-503.

Brown, P. R. A., and P. N. Francis, 1995: Improved measurements of the ice water content in cirrus using a total-water probe. $J$. Atmos. Oceanic Technol., 12, 410-414.

Campbell, J. R., D. L. Hlavka, E. J. Welton, C. J. Flynn, D. D. Turner, J. D. Spinhirne, V. S. Scott, and I. H. Hwang, 2002: Full-time eye-safe cloud and aerosol lidar observation at Atmospheric Radiation Measurement Program sites: Instrument and data processing. J. Atmos. Oceanic Technol., 19, 431-442.

Clothiaux, E. E., and Coauthors, 1999: The Atmospheric Radiation Measurement Program cloud radars: Operational modes. J. Atmos. Oceanic Technol., 16, 819-827.

Cober, S. G., G. A. Issac, and J. W. Strapp, 2001: Characterization of aircraft icing environments that include supercooled large drops. J. Appl. Meteor., 40, 1984-2002.

DeMott, P. J., K. Sassen, M. R. Poellot, D. Baumgardner, D. C. Rogers, S. D. Brooks, A. J. Prenni, and S. M. Kreidenweis, 2003: African dust aerosols as atmospheric ice nuclei. Geophys. Res. Lett., 30, 1732, doi:10.1029/2003GL017410.

Fox, N. I., and A. J. Illingworth, 1997: The retrieval of stratocumulus cloud properties by ground-based cloud radar. J. Appl. Meteor., 36, 485-492.

Frisch, A. S., C. W. Fairall, and J. B. Snider, 1995: Measurement of stratus cloud and drizzle parameters in ASTEX with a Kâa-band Doppler radar and a microwave radiometer. J. Atmos. Sci., 52, 2788-2799.

_, M. Shupe, I. Djalalova, G. Feingold, and M. Poellot, 2002: The retrieval of stratus cloud droplet effective radius with cloud radars. J. Atmos. Oceanic Technol., 19, 835-842.

Gossard, E. E., J. B. Snider, E. E. Clothiaux, B. Martner, J. S. Gibson, R. A. Kropfli, and A. S. Frisch, 1997: The potential of 8-mm radars for remotely sensing cloud drop size distributions. J. Atmos. Oceanic Technol., 14, 76-87.

Gregory, D., and D. Morris, 1996: The sensitivity of climate simulations to the specification of mixed phase clouds. Climate Dyn., 12, 641-651

Harrington, J. Y., T. Reisin, W. R. Cotton, and S. M. Kreidenweis, 1999: Cloud resolving simulations of Arctic stratus. Part II: Transition-season clouds. Atmos. Res., 51, 45-75.

Hildebrand, P. H., and R. S. Sekhon, 1974: Objective determination of the noise level in Doppler spectra. J. Appl. Meteor., 13, 808811.

Hobbs, P. V., and A. L. Rangno, 1985: Ice particle concentrations in clouds. J. Atmos. Sci., 42, 2523-2549.

Hogan, R. J., A. J. Illingworth, E. J. O'Connor, and J. P. V. Poiares
Baptista, 2003: Characteristics of mixed-phase clouds. Part II: A climatology from ground-based lidar. Quart. J. Roy. Meteor. Soc., 129, 1-18.

Houze, R. A., Jr., 1993: Cloud Dynamics. Academic Press, 573 pp.

Kollias, P., B. A. Albrecht, R. Lhermitte, and A. Savtchenko, 2001: Radar observations of updrafts, downdrafts, and turbulence in fair-weather cumuli. J. Atmos. Sci., 58, 1750-1766.

,$- \ldots$, and F. Marks Jr., 2002: Why Mie? Accurate observations of vertical air velocities and raindrops using a cloud radar. Bull. Amer. Meteor. Soc., 83, 1471-1483.

Korolev, A., and G. Isaac, 2003: Phase transformation of mixed-phase clouds. Quart. J. Roy. Meteor. Soc., 129, 19-28.

Lhermitte, R., 2002: Centimeter and Millimeter Wavelength Radars in Meteorology. Lhermitte Productions, $550 \mathrm{pp}$.

Liao, L., and K. Sassen, 1994: Investigation of relationships between Ka-band radar reflectivity and ice and liquid water contents. Atmos. Res., 34, 231-248.

Liu, C.-L., and A. J. Illingworth, 2000: Toward more accurate retrievals of ice water content from radar measurements of clouds J. Appl. Meteor., 39, 1130-1146.

Mace, G. G., A. J. Heymsfield, and M. R. Poellot, 2002: On retrieving the microphysical properties of cirrus clouds using the moments of the millimeter-wavelength Doppler spectrum. J. Geophys. Res., 107 (D24), 4815, doi:10.1029/2001JD001308.

Matrosov, S. Y., 1999: Retrievals of vertical profiles of ice cloud microphysics from radar and IR measurements using tuned regressions between reflectivity and cloud parameters. J. Geophys. Res., 104, 16 741-16 753

_ T. Uttal, J. B. Snider, and R. A. Kropfli, 1992: Estimation of ice cloud parameters from ground-based infrared radiometer and radar measurements. J. Geophys. Res., 97, 11 567-11 574.

__ A. V. Korolev, and A. J. Heymsfield, 2002: Profiling cloud ice mass and particle characteristic size from Doppler radar measurements. J. Atmos. Oceanic Technol., 19, 1003-1018.

_ M. D. Shupe, A. J. Heymsfield, and P. Zuidema, 2003: Ice cloud optical thickness and extinction estimates from radar measurements. J. Appl. Meteor., 42, 1584-1597.

Miles, N. L., J. Verlinde, and E. E. Clothiaux, 2000: Cloud droplet size distributions in low-level stratiform clouds. J. Atmos. Sci., 57, 295-311.

Moran, K. P., B. E. Martner, M. J. Post, R. A. Kropfli, D. C. Welsh, and K. B. Widener, 1998: An unattended cloud-profiling radar for use in climate research. Bull. Amer. Meteor. Soc., 79, 443455.

Morrison, H., M. D. Shupe, and J. A. Curry, 2003: Modeling clouds observed at SHEBA using a bulk microphysics parameterization implemented into a single-column model. J. Geophys. Res., 108 (D8), 4255, doi:10.1029/2002JD002229.

Pinto, J. O., 1998: Autumnal mixed-phase cloudy boundary layers in the Arctic. J. Atmos. Sci., 55, 2016-2038.

Rauber, R. M., and A. Tokay, 1991: An explanation for the existence of supercooled water at the top of cold clouds. J. Atmos. Sci. 48, 1005-1023.

Sassen, K., P. J. DeMott, J. M. Prospero, and M. R. Poellot, 2003: Saharan dust storms and indirect aerosol effects on clouds: CRYSTAL-FACE results. Geophys. Res. Lett., 30, 1633, doi: 10.1029/2003GL017371.

Shupe, M. D., and J. M. Intrieri, 2004: Cloud radiative forcing or the Arctic surface: The influence of cloud properties, surface albedo, and solar zenith angle. J. Climate, 17, 616-628.

cloud microphysics derived from surface-based remote sensors. Part II: Single- and mixed-phase cloud properties. J. Appl. Meteor., submitted.

Sun, Z., and K. P. Shine, 1994: Studies of the radiative properties of ice and mixed-phase clouds. Quart. J. Roy. Meteor. Soc., 120, $111-137$.

Westwater, E. R., Y. Han, M. D. Shupe, and S. Y. Matrosov, 2001: Analysis of integrated cloud liquid and precipitable water vapor retrievals from microwave radiometers during SHEBA. J. Geophys. Res., 106, 32 019-32030. 